\title{
A $2.45 \mathrm{GHz}$ microstrip antenna with harmonics suppression capability by using defected ground structure
}

\author{
Shaharil Mohd Shah', M. Mohamad², S. A. $\operatorname{Hamzah}^{3}$, Z. Z. Abidin', F. C. Seman ${ }^{5}$, N. Katiran \\ H. A. Majid ${ }^{7}$, A. Ashyap ${ }^{8}$, S. Mohamad ${ }^{9}$ \\ 1,2,3,4,5,7,8 Research Center for Applied Electromagnetics, Universiti Tun Hussein Onn Malaysia, Johor, Malaysia \\ ${ }^{6,9}$ Faculty of Electrical and Electronic Engineering, Universiti Tun Hussein Onn Malaysia, Johor, Malaysia
}

\begin{tabular}{l}
\hline \hline Article Info \\
\hline Article history: \\
Received Sep 9, 2019 \\
Revised Nov 3, 2019 \\
Accepted Dec 27, 2019 \\
\hline
\end{tabular}

Keywords:

Defected ground structure

Harmonics suppression

Higher order harmonics

Microstrip antenna

\begin{abstract}
In this work, a microstrip patch antenna with an inset feed and defected ground structure (DGS) is designed at the resonant frequency of $2.45 \mathrm{GHz}$. The antenna is designed on a FR-4 substrate with a dielectric constant, $\varepsilon \mathrm{r}$ of 4.5 , loss tangent, $\tan \delta$ of 0.019 and thickness, $\mathrm{h}$ of $1.6 \mathrm{~mm}$. The technique of DGS is used to avoid the use of additional circuits in the antenna to suppress the harmonics. By introducing a single and additional slots DGS at both ends on the antenna ground plane, the proposed microstrip patch antenna is able to suppress the higher order harmonics. The reflection coefficient, $\mathrm{S} 11$ is $-38.75 \mathrm{~dB}$ at $2.45 \mathrm{GHz}$. The proposed antenna have suppressed the higher order harmonics effectively from $-38.04 \mathrm{~dB}$ to $-2.61 \mathrm{~dB}$ at $4.54 \mathrm{GHz}$ and from $-13.08 \mathrm{~dB}$ to $-1.38 \mathrm{~dB}$ at $5.76 \mathrm{GHz}$. The prototype of the antenna is fabricated for the verification of the design. The simulated and measured results are found to be in a good agreement.
\end{abstract}

This is an open access article under the $\underline{C C B Y-S A}$ license.

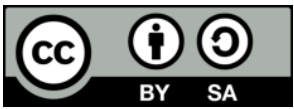

\section{Corresponding Author:}

Shaharil Mohd Shah,

Research Center for Applied Electromagnetics,

Universiti Tun Hussein Onn Malaysia,

86400 Batu Pahat, Johor, Malaysia.

Email: shaharil@uthm.edu.my

\section{INTRODUCTION}

The growth of wireless devices has been observed during the last decade. Energy that is delivered via free space does not required any physicaltransmission networks. However, the application of this system requires electrical signals to reach large distance from the antenna to radiate electromagnetic waves through free space. The best condition of transmitting antenna is when it produces power density that is detectable at great distance from the source [1]. However, the existence of electromagnetic interference that is caused by harmonic radiation is the main issue in microwave system. The procedure of the antenna arrangement is presupposed to be effective and the losses of energy should be reduced by suppressing the unwanted harmonics signal. The unwanted harmonics signal or noise radiated through antenna is generated by the power amplifier that produces higher order harmonics in the system [2]. Generally, the harmonic signals are inhibited by the circuit of harmonic filter which is connected to the antenna and the connection must be perfectly fitted so that the maximum power can be shifted between them, or otherwise another matching circuit need to be put between these circuits [3]. The introduction of an additional circuit to the system will increase the cost, size, complexity and weight of the system [4].

In order to suppress the unwanted signals of higher order harmonics in a microstrip antenna, a few techniques have been proposed such as stacking [5], frequency selective surface (FSS) [6], electromagnetic band gap (EBG) [7], photo band gap (PBG) [8] and metamaterial [9]. One of them is by 
using the defected ground structure (DGS) on the antenna itself due to its simple physical design [10]. A few structures of DGS have been proposed in the past such as the T-shaped DGS [11-12], H-shaped DGS [13], U-slot DGS [14-15], and circular slot DGS [16-19]. The DGS has attractive properties in terms of size miniaturization, suppression of surface waves and the ability to present distinctive stop bands [20]. In DGS, the modification is made on the under plane of the antenna to boost the performance by suppressing the higher order harmonics. The basic element of DGS is the resonant slot or gap that is placed on the ground plane [21]. They are placed directly under the transmission line and aligned for efficient line coupling [22].

\section{RESEARCH METHODOLOGY}

The antennas in this work are designed and simulated in CST Microwave Studio® software. In order to arrive at the final design of an antenna with DGS, an inset feed microstrip antenna without DGS is proposed. The design process of this antenna is based on the dimensions of the microstrip antenna from the calculation and optimization method. The DGS is then introduced on the ground plane of the optimized inset feed microstrip antenna to suppress the higher order harmonics. The linear characteristics of the antenna are then investigated in terms of reflection coefficient, radiation pattern, gain, efficiency and surface current distributions.

\subsection{Inset feed microstrip antenna without defected ground structure (DGS)}

Figure 1 shows the design and dimensions of the inset feed microstrip antenna in this work. The inset feed configuration is chosen in this work to improve the impedance matching of the antenna in order to get a better reflection coefficient [25]. Table 1 lists the dimension values of the antenna. Dimensions of the ground plane is the same as the dimensions of the substrate which is $57.3 \times 57.3 \mathrm{~mm}^{2}$.

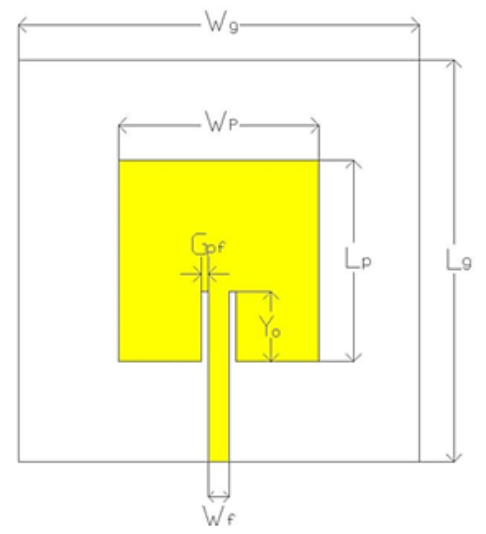

Figure 1. Inset feed microstrip antenna without DGS

Table 1. Dimensions of the inset feed optimized microstrip antenna

\begin{tabular}{cc}
\hline Parameter & Values $(\mathrm{mm})$ \\
\hline $\mathrm{W}_{\mathrm{p}}$ & 28.65 \\
$\mathrm{~L}_{\mathrm{p}}$ & 28.65 \\
$\mathrm{~W}_{\mathrm{g}}$ & 57.3 \\
$\mathrm{~L}_{\mathrm{g}}$ & 57.3 \\
$\mathrm{~W}_{\mathrm{f}}$ & 3 \\
$\mathrm{G}_{\mathrm{pf}}$ & 1 \\
$\mathrm{Y}_{\mathrm{o}}$ & 10 \\
$\mathrm{~W}_{\mathrm{p}}$ & 28.65 \\
\hline
\end{tabular}

\subsection{Inset feed microstrip antenna with defected ground structure (DGS)}

In the next antenna design, a defected ground structure (DGS) is introduced into the ground plane to suppress the higher order harmonics produced between the frequency range of wireless communica tion from 1 to $6 \mathrm{GHz}$. In order to reach at the final design, a parametric study has been conducted to get the best result. Two antenna designs have been proposed which can be viewed in Figure 2. Figure 2(a) shows a single slot DGS which has been optimized. On the other hand, Figure 2(b) illustrates the additional dimensions 
at the right and left end of the initial slot. The additional dimensions are found to be able to further improve the harmonics suppression. The dimensions of the antennas are listed in Table 2. The position of the slot has been varied to find the best location to suppress the higher order harmonics. Figure 3 shows the variation of slot that is placed under the feed line. The reference point is at the edge of the feed line with $\mathrm{x}=0 \mathrm{~mm}$. The position is then varied at $1.5 \mathrm{~mm}, 3.0 \mathrm{~mm}, 4.5 \mathrm{~mm}, 6.0 \mathrm{~mm}$ and $7.5 \mathrm{~mm}$. It is found that the location of the slot at $6.0 \mathrm{~mm}$ gives the best result as it can suppress the higher order harmonics greatly. Table 2 lists the dimensions of both DGS on the ground plane of the antenna.

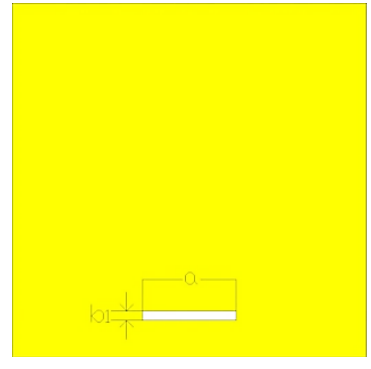

(a)

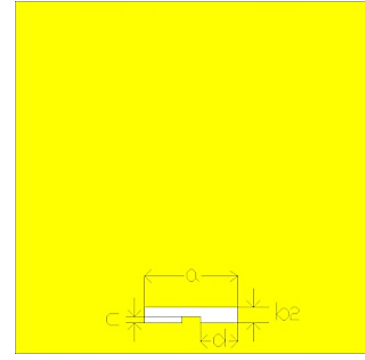

(b)

Figure 2. Inset feed microstrip antenna with DGS, (a) A single slot DGS, (b) A single slot with additionalslot DGS at both ends

Table 2. Dimensions of the DGS of the inset feed microstrip antenna in Figure 2

\begin{tabular}{cc}
\hline Parameter & Values $(\mathrm{mm})$ \\
\hline $\mathrm{a}$ & 15 \\
$\mathrm{~b}_{1}$ & 1.5 \\
$\mathrm{~b}_{2}$ & 2.5 \\
$\mathrm{c}$ & 1 \\
$\mathrm{~d}$ & 6 \\
\hline
\end{tabular}

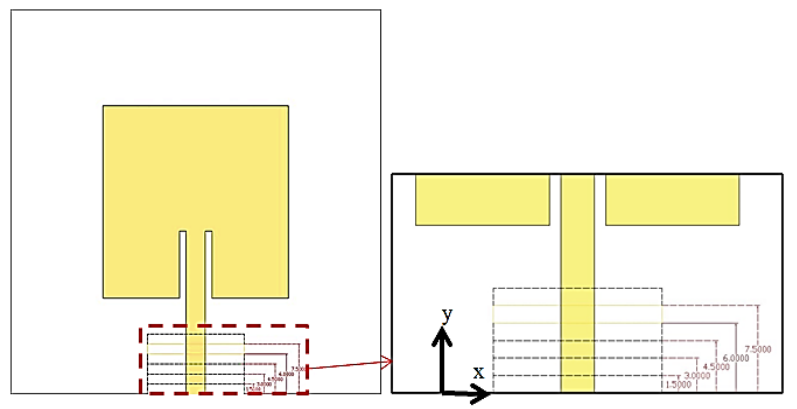

Figure 3. Position variations of a single slot DGS on the ground plane of the microstrip patch antenna

\subsection{Antenna fabrication and measurement}

The antennas involved in this work are fabricated on a FR-4 substrate with a thickness, $\mathrm{h}$ of $1.6 \mathrm{~mm}$, dielectric constant, $\varepsilon_{\mathrm{r}}$ of 4.5 and loss tangent, $\tan \delta$ of 0.019 by using the printed circuit board (PCB) technology. The performance of these antennas are investigated by measuring the linea $r$ characteristics. The measurements are conducted by using the ZVB14 Rohde \& Schwarz Vector Network Analyzer (VNA) and the results are analyzed. Figure 4 shows all the fabricated antennas in this work.

\section{RESULTS AND ANALYSIS}

In this section, the reflection coefficients of the fabricated microstrip antennas are measured and compared with the simulation results. In order to simplify the analysis, only the linear characteristics 
of the final antenna (the inset feed microstrip antenna with a single and additional slot DGS at both ends) are presented and analysed.

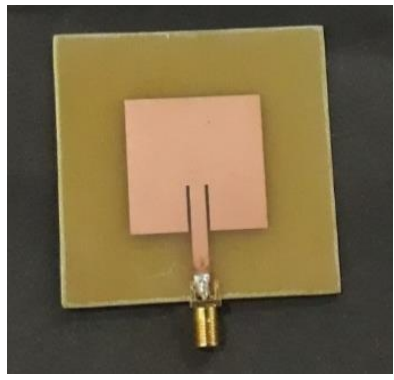

(a)

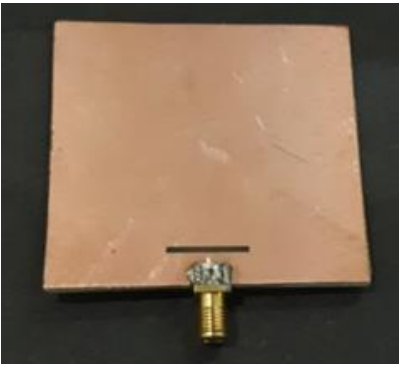

(d)

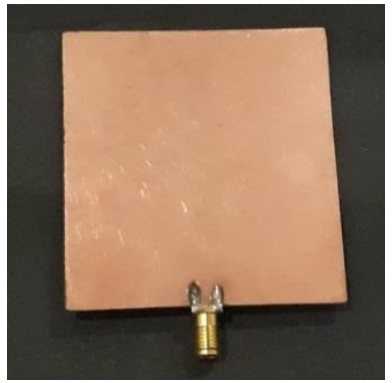

(b)

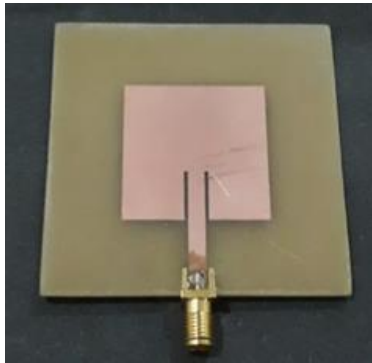

(e)

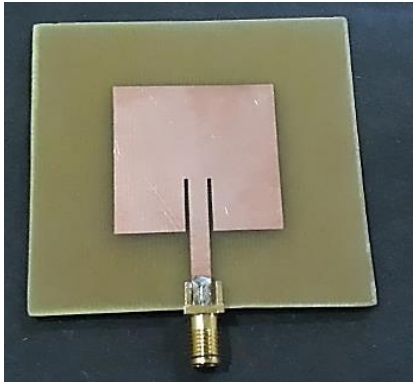

(c)

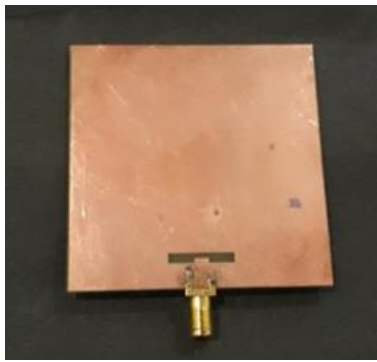

(f)

Figure 4. Fabricated inset feed microstrip antennas, (a) Without DGS (front view), (b) With DGS (back view), (c) With a single slot DGS (front view), (d) With a single slot DGS (back view),

(e) With a single and additionalslot DGS at both ends (front view), (f) With a single and additional slot DGS at both ends (back view)

\subsection{Inset feed microstrip antenna without defected ground structure (DGS)}

Figure 5 shows the comparison between the simulated and measured reflection coefficients of the inset feed microstrip antenna without DGS. From the figure, it can be seen that there is a slight shift in the measured resonant frequency of the fabricated antenna from $2.45 \mathrm{GHz}$ to $2.51 \mathrm{GHz}$ with $\mathrm{S}_{11}$ of -18.30 $\mathrm{dB}$. This discrepancy can be attributed to the fabrication tolerances and cable losses during the measurement process. In addition, the higher order harmonics can be seen to be located at $4.54 \mathrm{GHz}$ with $\mathrm{S}_{11}$ of $-38.04 \mathrm{~dB}$ and $5.76 \mathrm{GHz}$ with $\mathrm{S}_{11}$ of $-13.08 \mathrm{~dB}$.

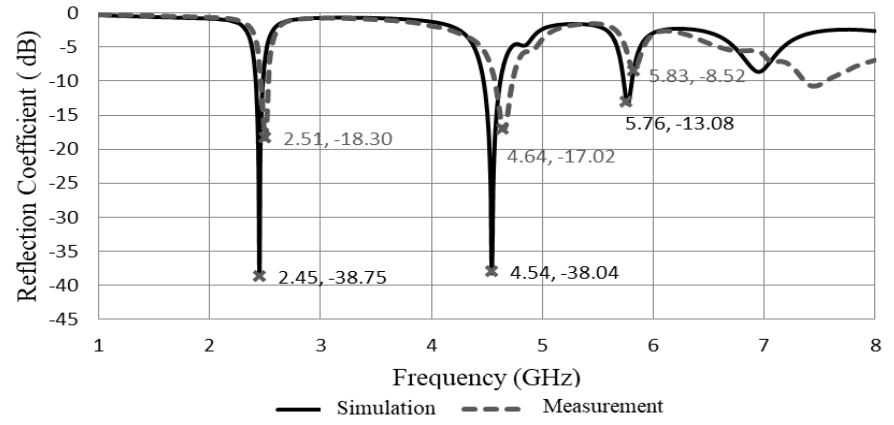

Figure 5. Comparison between the simulated and measured reflection coefficients of the microstrip patch antenna with an inset feed 


\subsection{Inset feed microstrip antenna with a single slot DGS}

The fabricated inset feed microstrip antenna with a single slot DGS antenna is measured. Figure 6 shows the comparison between measured and simulated reflection coefficients of the antenna with a good agreement between the two. From the figure, the resonant frequency has been slightly shifted to $2.54 \mathrm{GHz}$ with $S_{11}$ of $-21.72 \mathrm{~dB}$. Furthermore, it can be seen that the $S_{11}$ at $2.45 \mathrm{GHz}$ is $-24.19 \mathrm{~dB}$ and the $S_{11}$ at higher order harmonics of $4.54 \mathrm{GHz}$ and $5.76 \mathrm{GHz}$ have been suppressed to $-3.34 \mathrm{~dB}$ and $-1.38 \mathrm{~dB}$, respectively. Figure 7 compares the reflection coefficient of the microstrip patch antenna with and without the DGS.

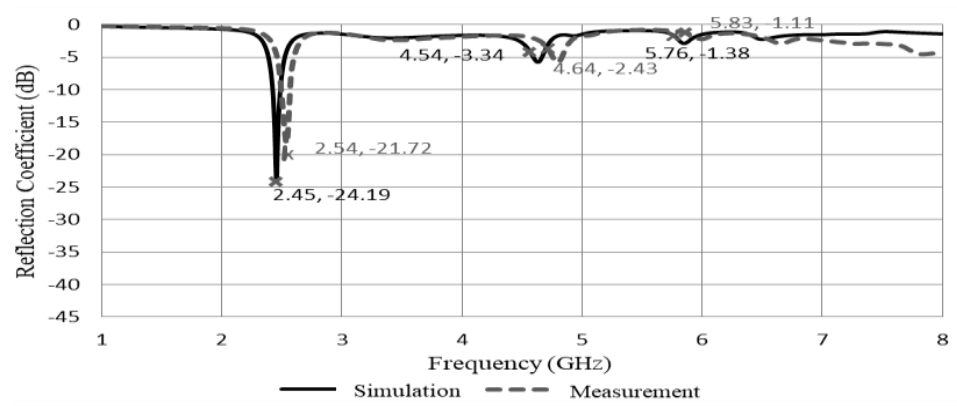

Figure 6. Comparison between the simulated and measured reflection coefficients of the microstrip patch antenna with a single slot DGS

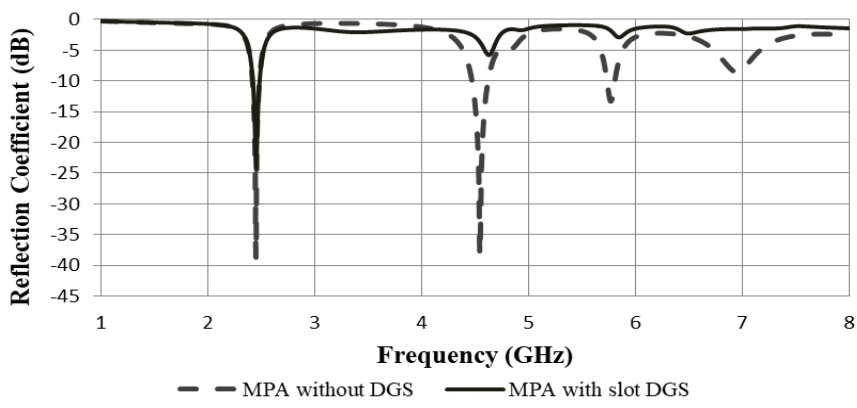

Figure 7. Reflection coefficient of the inset feed microstrip antenna with and without the single slot DGS

\subsection{Inset feed microstrip antenna with a single and additional slot DGS at both ends}

Figure 8 shows the comparison between the simulated and measured reflection coefficients of the inset feed microstrip patch antenna with a single and additional slot DGS at both ends. From the figure, the measured resonant frequency has been slightly shifted to $2.51 \mathrm{GHz}$ with $\mathrm{S}_{11}$ of $-21.72 \mathrm{~dB}$. Moreover, it can be clearly seen that the existing suppressed harmonics have been further reduced to $-2.61 \mathrm{~dB}$ at $4.54 \mathrm{GHz}$ and remains at a relatively lower $\mathrm{S}_{11}$ of $-1.38 \mathrm{~dB}$ at $5.76 \mathrm{GHz}$. The measured and simulated results are found to be in a good agreement.

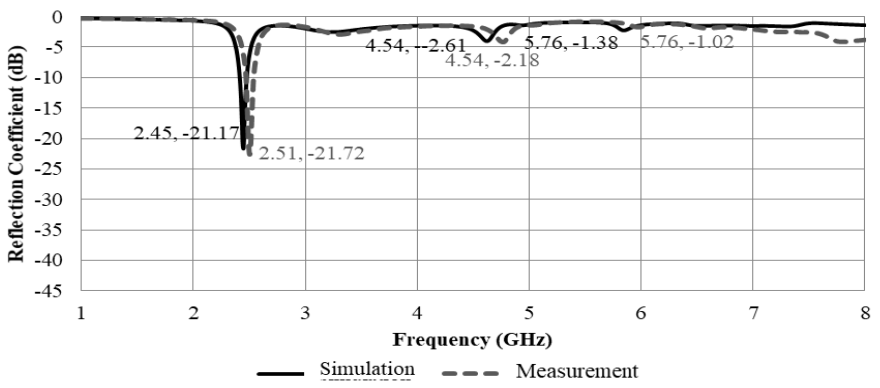

Figure 8. Comparison between the simulated and mea sured reflection coefficients of the microstrip antenna with a single slot and additionalslot DGS at both ends 
The radiation patterns of the antenna in the E-plane and H-plane can be viewed in Figure 9. The main lobe magnitudes for both planes are similar at $6.39 \mathrm{dBi}$. It can be seen from the figure that the radiation pattern in the E-plane is almost unidirectional and omnidirectional pattern is observed in the $\mathrm{H}$-plane. The current distribution at resonant frequency and higher order harmonics of the antenna ca $\mathrm{n}$ be observed in Figure 10. From the figure, the maximum current is seen to be concentrated at the edge of the inset feed at the fundamental frequency of $2.45 \mathrm{GHz}$. No maximum current are seen on the surface of the antenna at higher order harmonics of $4.54 \mathrm{GHz}$ and $5.76 \mathrm{GHz}$ which imply that harmonics at those frequencies are suppressed.

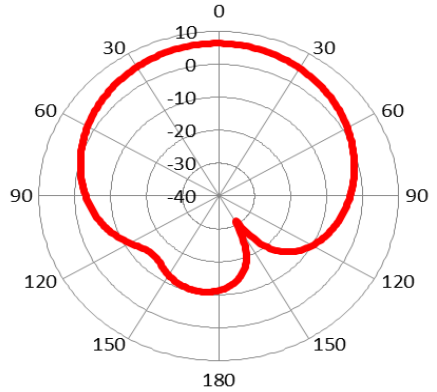

(a)

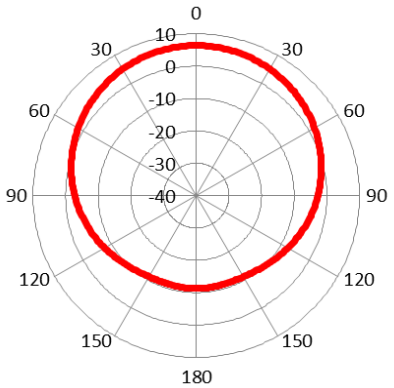

(b)

Figure 9. Radiation pattern of the microstrip antenna with a single and additionalslot DGS at both ends at the fundamental frequency of $2.45 \mathrm{GHz}$ in the, (a) E-plane, (b) H-plane

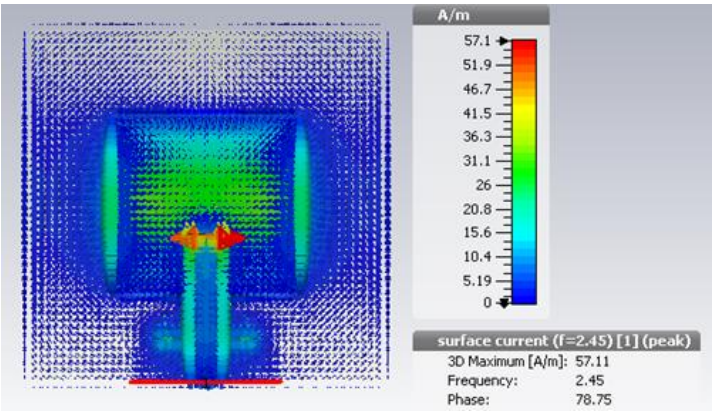

(a)

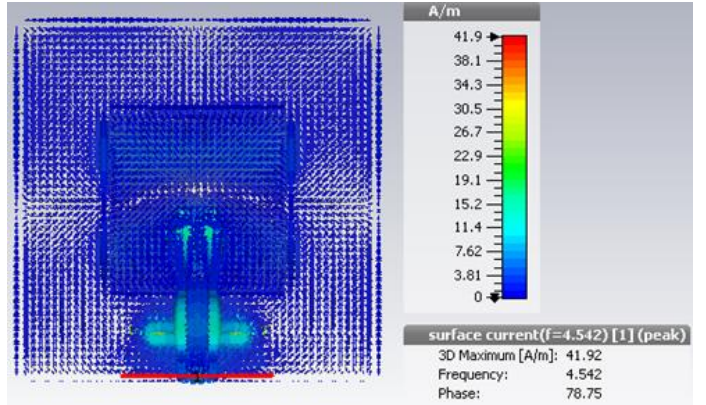

(b)

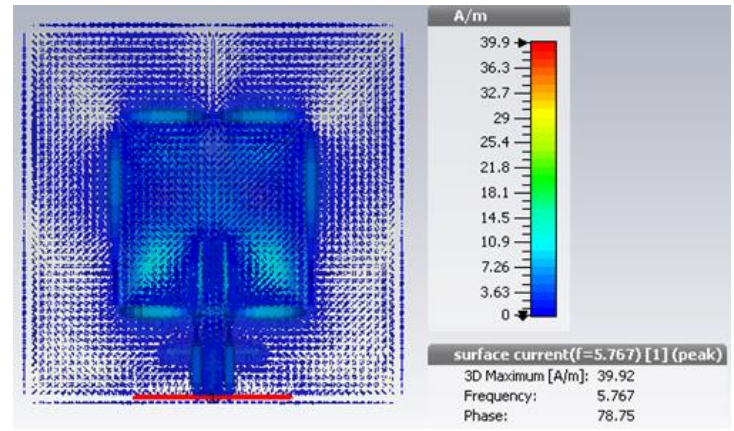

(c)

Figure 10. Simulated surface current of the microstrip antenna with a single and additionalslot DGS at both ends at, (a) $2.45 \mathrm{GHz}$, (b) $4.54 \mathrm{GHz}$, (c) $5.76 \mathrm{GHz}$

\section{CONCLUSION}

In this work, the microstrip antenna with an inset feed and defected ground structure (DGS) has been designed, simulated and fabricated on a FR-4 substrate and measured by using the ZVB14 Rohde 
\& Schwarz VNA. The antenna operates at $2.45 \mathrm{GHz}$ with a reflection coefficient of $-38.75 \mathrm{~dB}$ and produces higher order harmonics at $4.54 \mathrm{GHz}$ and $5.76 \mathrm{GHz}$. The geometry of the defected ground structure (DGS) has been optimized to get the best result in terms of harmonics suppression. The microstrip patch antenna integrated with a single slot and additional slot at both ends of DGS is found to have further suppressed the higher order harmonics as compared to a single slot DGS. The proposed antenna with DGS has suppressed the higher order harmonics effectively from $-38.04 \mathrm{~dB}$ to $-2.61 \mathrm{~dB}$ at $4.54 \mathrm{GHz}$ and from $-13.08 \mathrm{~dB}$ to $-1.38 \mathrm{~dB}$ at $5.76 \mathrm{GHz}$.

\section{ACKNOWLEDGEMENT}

The author would like to acknowledge Universiti Tun Hussein Onn Malaysia for the funding of this work under the InternalGrant of Tier 1 (H247).

\section{REFERENCES}

[1] Stutzman, W. L., \& Thiele, G. A, “Antenna Theory and Design,” $3^{\text {rd }}$ Edition, John Wiley \& Sons, May 2012.

[2] Younkyu Chung et al., "AlGaN/GaN HFET power amplifier integrated with microstrip antenna for RF front-end applications," in IEEE Transactions on Microwave Theory and Techniques, vol. 51, no. 2, pp. 653-659, Feb. 2003.

[3] Singh, I., \& Tripathi, V. S., "Micro strip Patch Antenna and Its Applications: A Survey," in International Journal of Computer Applications in Technology, vol. 2, no. 5, pp. 1595-1599, September 2011.

[4] Weng, L. H., Guo, Y. C., Shi, X. W., \& Chen, X. Q., “An overview on defected ground structure," in Progress In Electromagnetics Research, vol. 7, pp. 173-189, January 2008.

[5] J. Shi, J. Chen and Q. Xue, "A quasi-elliptic function dual-band bandpass filter stacking spiral-shaped CPW defected ground structure and back-side coupled strip lines," in IEEE Microwave and Wireless Components Letters, vol. 17, no. 6, pp. 430-432, June 2007.

[6] K. Sarabandi and N. Behdad, "A frequency selective surface with miniaturized elements," in IEEE Transactions on Antennas and Propagation, vol. 55, no. 5, pp. 1239-1245, May 2007.

[7] Fan Yang and Y. Rahmat-Samii, "Microstrip antennas integrated with electromagnetic band-gap (EBG) structures: a low mutual coupling design for array applications," in IEEE Transactions on Antennas and Propagation, vol. 51, no. 10, pp. 2936-2946, Oct. 2003.

[8] Yongxi Qian, D. Sievenpiper, V. Radisic, E. Yablonovitch and T. Itoh, "A novel approach for gain and bandwidth enhancement of patch antennas," Proceedings RAWCON 98. 1998 IEEE Radio and Wireless Conference (Cat. No.98EX194), Colorado Springs, CO, USA, pp. 221-224, 1998.

[9] J. Zhu and G. V. Eleftheriades, "A compact transmission-line metamaterial antenna with extended bandwidth," in IEEE Antennas and Wireless Propagation Letters, vol. 8, pp. 295-298, 2009.

[10] Yong-Chae Jeong, Si-Gyun Jeong, Jong-Sik Lim and Sangwook Nam, "A new method to suppress harmonics using /spl lambda//4 bias line combined by defected ground structure in power amplifiers," in IEEE Microwave and Wireless Components Letters, vol. 13, no. 12, pp. 538-540, Dec. 2003.

[11] Hyung-Mi Kim and Bomson Lee, "Analysis and synthesis of defected ground structures (DGS) using transmission line theory," 2005 European Microwave Conference, Paris, pp. 4, 2005.

[12] N. Zainol, Z. Zakaria, M. Abu, M. M. Yunus and E. Ruslan, "Design of $2 \times 2$ array antenna with harmonic suppression using T-shape DGS and spurline," 2017-11th European Conference on Antennas and Propagation (EUCAP), Paris, pp. 1044-1048, 2017.

[13] Prajapati, P. R., "Application of defected ground structure to suppress out-of-band harmonics for WLAN microstrip antenna," In International Journal of Microwave Science and Technology, vol. 2015, no. 5-6, pp. 1-9, December 2015.

[14] A. Boutejdar, A. Ramadan, M. Makkey and A. S. Omar, "Design of compact microstrip lowpass filters using a U-shaped defected ground structure and compensated microstrip line," 2006 European Microwave Conference, Manchester, pp. 267-270, 2006.

[15] Rahim, R. A., Hassan, S. I. S., Junita, M. N., Hassan, H. F., \& Tazi, A. I. A., "A U-Slot DGS and circular-slot on patch for harmonic suppression microstrip patch antenna," In IEEE Colloquium on Humanities, Science \& Engineering Research (CHUSER), April 2014

[16] D. Guha, M. Biswas and Y. M. M. Antar, "Microstrip patch antenna with defected ground structure for cross polarization suppression," in IEEE Antennas and Wireless Propagation Letters, vol. 4, pp. 455-458, 2005

[17] S. Biswas, D. Guha and C. Kumar, "Control of higher harmonics and their radiations in microstrip antennas using compact defected ground structures," in IEEE Transactions on Antennas and Propagation, vol. 61, no. 6, pp. 33493353, June 2013.

[18] C. Sim, M. Chang and B. Chen, "Microstrip-fed ring slot antenna design with wideband harmonic suppression," in IEEE Transactions on Antennas and Propagation, vol. 62, no. 9, pp. 4828-4832, Sept. 2014.

[19] R. A. Rahim, F. Malek, S. F. W. Anwar, S. L. S. Hassan, M. N. Junita and H. F. Hassan, "A harmonic suppression circularly polarized patch antenna for an RF ambient energy harvesting system," 2013 IEEE Conference on Clean Energy and Technology (CEAT), Lankgkawi, pp. 33-37, 2013. 
[20] El-Shaarawy, Heba B., et al., "Defected ground structures (DGS) and uniplanar compact-photonic band gap (UC-PBG) structures for reducing the size and enhancing the out-of-band rejection of microstrip bandpass ring resonator filters," in WSEAS Transactions on Communications, vol. 7, no. 11, pp. 1112-1121, November 2008.

[21] Pandhare, Rashmi A., Prasanna L. Zade, \& Mahesh P. Abegaonkar, "Miniaturized microstrip antenna array using defected ground structure with enhanced performance," Engineering Science and Technology, an International Journal, vol. 19, no. 3, pp. 1360-1367, September 2016.

[22] Breed, G., "An introduction to defected ground structures in microstrip circuits," High Frequency Electronics, vol. 7, pp. 50-54, 2008.

[23] U. Pattapu, A. Gupta and S. Das, "A $2.45 \mathrm{GHz}$ harmonic suppression array antenna for rectenna application," 2018 3rd International Conference on Microwave and Photonics (ICMAP), Dhanbad, pp. 1-2, 2018.

[24] Gao, Yan-Yan, et al., "A circularly polarized rectenna with low profile for wireless power transmission," in Progress In Electromagnetics Research Letters, vol. 13, pp. 41-49, January 2010.

[25] Ying Hu, D. R. Jackson, J. T. Williams and S. A. Long, "A design approach for inset-fed rectangular microstrip antennas," 2006 IEEE Antennas and Propagation Society International Symposium, Albuquerque, NM, pp. 14911494, 2006.

\section{BIOGRAPHIES OF AUTHORS}
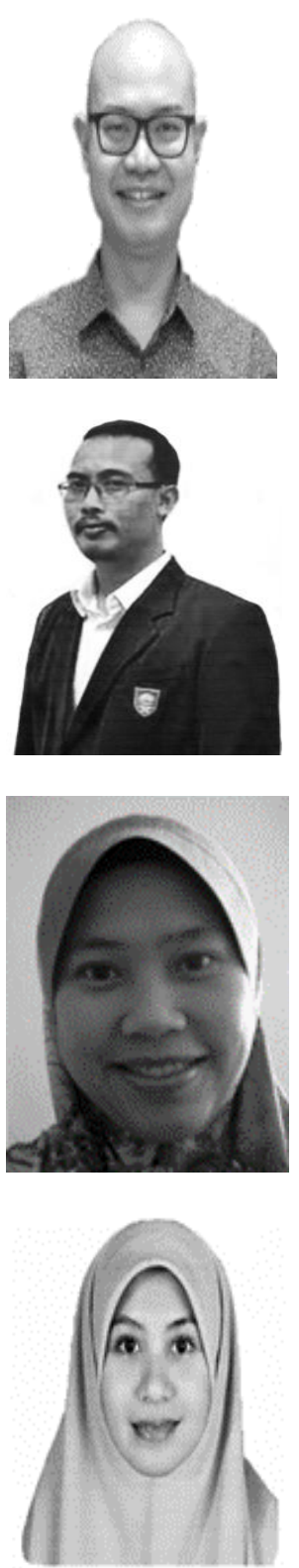

Shaharil Mohd Shah, obtained his B. Eng in Microwave and Communication from Multimedia University (MMU) in 2002. He received his M.Sc in Microwave Engineering and Wireless Subsystems Design from the University of Surrey, UK in 2004 and pursuing his Ph.D in Communication Engineering from the University of Birmingham, UK before graduating in 2016. $\mathrm{He}$ is currently a senior lecturer in the Department of Communication Engineering, Faculty of Electrical and Electronic Engineering, Universiti Tun Hussein Onn Malaysia (UTHM). His area of research includes, but not limited to, design of microwave devices, active antennas measurement and nonlinear characterisation of active devices.

Shipun Anuar Hamzah, was born in Perak, Malaysia in 1975. He received the B.Eng. and Ph.D. in electrical engineering from Universiti Teknologi Malaysia (UTM), Malaysia in 1998 and 2013, respectively and M.Eng. of Engineering in Communication and Computer System from National University of Malaysia (UKM), Selangor, Malaysia, in 2000. From 1998 to 2004, he worked as a lecturer at Kolej UNITI Sdn. Bhd, Malaysia. Since April 2004, he has been working as a Lecturer at the Faculty of Electrical and Electronic Engineering, Universiti Tun Hussein Onn Malaysia (UTHM). He is now a Senior Lecturer with the same institution. His research interests include active antenna, harmonic suppression antenna, rectifying-antenna and RF propagation.

Zuhairiah Zainal Abidin, was born in Kuala Lumpur, Malaysia, in 1978. She received the B.Eng.from the Universiti Teknologi Malaysia, in 2001, the M. Eng from the Kolej Universiti Tun Hussein Onn Malaysia, Johor, Malaysia, in 2003, and Ph.D. degree from Bradford University, U.K in 2011. Currently, she was a Principal Researcher at Applied Electromagnetic Center, Universiti Tun Hussein Onn Malaysia. She has authored and co-authored numbers of journals and proceedings, including the IEEE TRANSACTION ON ANTENNA AND PROPAGATION, MICROWAVE AND OPTICAL TECHNOLOGY LETTERS and IEEE AWPL. Her research interests include MIMO antenna, printed microstrip antenna, wearable antennas, electromagnetic bandgap (EBG) for wireless and mobile and high speed digital circuit's applications.

Fauziahanim Che Seman, received the B.Eng. degree in electrical communication from Universiti Teknologi Malaysia. In 2002, she was awarded M.Eng. degree in communication engineering from Kolej Universiti Tun Hussein Onn, now known as Universiti Tun Hussein Onn (UTHM). She received her Ph.D. in electrical engineering Queens University, Belfast, Northern Ireland in 2011. She serves as academician in Department of Communication Engineering, Faculty of Electrical Electronic Engineering at Universiti Tun Hussein Onn Malaysia (UTHM) since 2002. She is also a research fellow in Research Center for Applied Electromagnet (EMCenter She is actively involves with industrial-academia activities and currently has joint research collaboration with Telekom Malaysia RnD. Her research interests include frequency selective surfaces, antenna design and applied electromagnetics. 

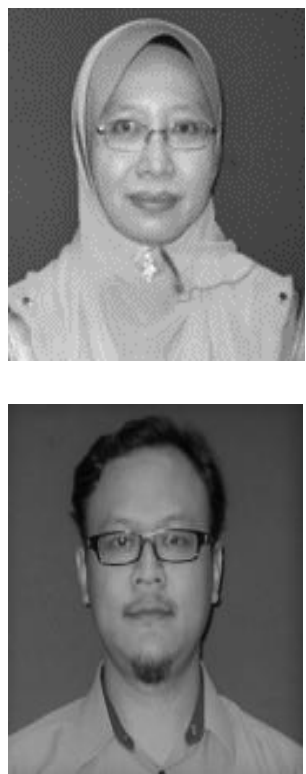

Norshidah Katiran, received her Ph.D in Electrical Engineering from Universiti Teknologi Malaysia, in 2015, her M.Eng. degree in Communication and Computer Engineering from Universiti Kebangsaan Malaysia, in 2004, and her B.Eng. degree in Electrical Engineering (Telecommunications) from Universiti Teknologi Malaysia, in 2001. Currently, she is a Senior Lecturer in the Department of Communication Engineering at Universiti Tun Hussein Onn Malaysia. Her major research interests include optimization of resource allocation in cooperative networks and multiple input multiple output (MIMO) transmissions.

Huda A Majid, received the B Eng. degree in Electrical Engineering (Telecommunication) from Universiti Teknologi Malaysia, in 2007. He then obtained his M.Eng in 2010 and PhD degrees in Electrical Engineering in 2013, at Universiti Teknologi Malaysia. He is currently a lecturer in the Department of Electrical Engineering Technology, Faculty of Engineering Technology, Universiti Tun Hussein Onn Malaysia. His research interest includes the areas of design of microstrip antennas, small antennas, Reconfigurable antennas, metamaterials structure, metalaterial antennas and millimeter wave antennas. He has published over 90 articles in journals and conference papers. 